\title{
ECONOMIC AND ENERGY EFFICIENCY OF PHOSPHOENTERIN ADMINISTRATION IN GROWING SPRING BARLEY OF STALKER VARIETY
}

\author{
M. I. Baranska ${ }^{1}$, Y. M. Halep ${ }^{2}$, L. A. Chaikovskaya ${ }^{1}$
}

Today the priority of agricultural production is getting high yields of crops keeping the requirements of product quality. The increasing popularity becomes a solution to this problem as the use biological agents manufactured on the basis of efficient strains of microorganisms. So, to improve phosphorous mineral nutrition of plants biological agents based on microorganisms that transform low-soluble phosphates into the forms available to plants are used [1;2]. It is established that the use of microbial agents can reduce mineral fertilization, and this is an important reserve for their economy [3]. In field experiments positive influence of biological agent Phosphoenterin based on phosphate-mobilizing bacteria Enterobacter nimipressuralis 32-3 to crops yield was revealed [4-6].

It is known that one of the major criteria for evaluating the recommended tools for increasing productivity of agro-ecosystems under market conditions is economic efficiency, which accumulates most economically valuable product qualities. Along with the economic assessment, it is also advisable to conduct the study of bioenergetic efficiency of agricultural activities, including the return of anthropogenic energy expenditure by obtained harvest. Bioenergetic assessment provides an objective idea about the effectiveness and appropriateness of certain agricultural activities unlike economic exercised in value terms, depending on market conditions, inflation and so on. In this regard, the objective of the research was to study the economic and energy efficiency of biological agent Phosphoenterin use for growing spring barley on different agricultural backgrounds in the conditions of Southern Steppes of Ukraine.

Materials and methods. Field experiments were conducted on the experimental field of the Institute of irrigated agriculture of NAAS (Kherson region) in 2006-2009. Research field soil: dark chestnut slightly alkalinized medium loamy. Crop - spring barley, Stalker variety. In field experiments the following agricultural backgrounds were used (as recommended by
Institute scientists): no fertilizer; $\mathrm{N}_{30} \mathrm{P}_{30}$; the estimated dose of fertilizers $\left(\mathrm{N}_{53}\right.$ on average for 3 years of research).

To determine the economic efficiency of Phosphoenterin use in the technology of spring barley growing the calculations were done according to the methods $[7 ; 8]$, based on the comparison of the results of agricultural activity with the costs of its implementation by the following parameters: product unit cost, profit at the rate of 1 ton of product and 1 hectare of cultivated area, manufacture profitability and return of additional costs when calculating costs associated with the use of Phosphoenterin. Included were the changes not only of those indicators that are directly related to bacterization (direct costs: cost of agent, processing costs, costs for transportation and additional harvest heritage), but also changes in overhead costs, which are distributed proportionally to direct ones in the calculation of production costs. For this purpose the full cost is calculated as profit, which is primarily interesting for agent consumer is the difference between the price and the total cost of products. Such methodological and methodical approach slightly increases the calculation level of expenses for the use of Phosphoenterin, but at the same time contributes to an objective assessment of its economic performance.

Technological operations of expenses were adopted according to regulations of National Science Centre "Institute of Agrarian Economy" of NAAS $[9 ; 10]$ with the inclusion of additional, direct and overhead costs that are associated with the use of Phosphoenterin. To study the energetic effectiveness of Phosphoenterin use technological operations and related resource consumption (calculated in the process of economic evaluation) were transferred into their energy equivalents according to the appropriate methods [11-13]. The level of productivity in the control and experimental variants was adopted at the average level, according to three-year experiments.

Consequently, the application of 
Phosphoenterin contributes to a noticeable Phosphoenterin use in spring barley of Stalker increase in energy efficiency of spring barley variety growing, it should be concluded that the growing - on all three agricultural backgrounds study agent is highly effective both by economic energy efficiency coefficients in research variants and energy criteria. At this the highest efficiency were higher than in control ones. This is due to in the conditions of experiments on dark chestnut higher yield energy growth rate associated with soil is observed at the average level of nitrogen the use of the agent.

fertilizer $\left(\mathrm{N}_{53}\right)$ without introducing phosphate

Summarizing the results of the conducted fertilizers. analysis of economic and energy efficiency of 